Amy McGaha, MD, assistant director of the AAFP Division of Medical Education, who had a leading role in developing the report, said that the recommendations are a critical step to help balance physician workforce needs.

"It is painfully clear that the country is moving in the wrong direction on all fronts - in the number of students choosing (family medicine and other primary care specialties), in supporting the kind of training needed, and in supporting physicians in practice in delivering the care that is needed," she said. "Our first order of business must be to reverse these trends."

Current AAFP policy states that the Academy should regularly assess and report on the family physician workforce. This most recent update comes at a particularly critical time, the report notes, because of the national discussion about health care delivery, physician practices, and patient access.

"These changes require a workforce policy with greater specificity in its recommendations and present an opportunity to positively impact both national and state health policy," says the report. "Addressing the national health workforce is a recognition of health care as a public good and (an acknowledgement) that maintaining a sufficient number of well-trained and appropriately deployed family physicians is in the public's best interest."

Barbara Bein

AAFP News Now

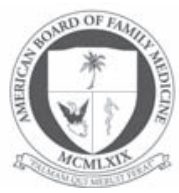

From the American

Board of Family Medicine

Ann Fam Med 2010;8:87. doi:10.1370/afm.1084.

\section{ABFM AND ABIM TO JOINTLY PARTICIPATE IN RECOGNITION OF FOCUSED PRACTICE (RFP) IN HOSPITAL MEDICINE PILOT APPROVED BY ABMS}

The American Board of Family Medicine (ABFM) is joining forces with the American Board of Internal Medicine (ABIM) in establishing a pilot program for Recognition of Focused Practice (RFP) in hospital medicine. This pilot was approved by the American Board of Medical Specialties (ABMS) Board of Directors on September 23, 2009.

Recognition of Focused Practice (RFP) in hospital medicine will utilize the current maintenance of certi- fication framework and would be the first customized maintenance of certification (MOC) pathway that draws heavily on practice-based learning as its foundation. The pilot would engage hospitalists in uniquely designed Part II, Part III, and Part IV tools that will be developed by the ABFM and ABIM.

Recent statistics indicate rapid growth and development in the field of hospital medicine, with about 20,000 hospitalists in the United States. "Given the significant number of family physicians working exclusively in the hospital setting, our board of directors felt it important to participate fully in this pilot with the ABIM," said James C. Puffer, MD, President and CEO of the ABFM. "We envision working together closely to develop the special tools used by our diplomates in this customized MOC pathway."

In order to attain hospital medicine recognition, ABFM Diplomates must complete residency training in family medicine, be certified in family medicine, and participate in a practice that focuses primarily on hospital medicine for a minimum of 3 years. Diplomates interested in pursuing RFP may apply to the program in 2010. Approval for the program requires an attestation by the Diplomate and a senior hospital officer that the Diplomate meets thresholds for family medicine practice in the hospital setting and professional commitment to hospital medicine.

Program requirements for ABFM Recognition of Focused Practice in Hospital Medicine will include the following:

- Certification by the American Board of Family Medicine (ABFM) —Diplomates must be in good standing and must maintain their primary certification in family medicine by the ABFM

- Currently valid, full, and unrestricted license to practice medicine in the United States or Canada

- ACLS certification

- Minimum of 3 years of hospital medicine experience

- Attestation by the Diplomate and a senior hospital officer that the Diplomate meets thresholds for family medicine practice in the hospital setting and professional commitment to hospital medicine

- Maintenance of certification activity comprised of self-assessment of medical knowledge and practice performance relevant to hospital medicine

- Passing an ABFM MOC examination in hospital medicine

Completion of the program would identify Diplomates as certified in family medicine with focused practice in hospital medicine. The pilot program will begin in the fall of 2010 .

Jane Ireland 